\title{
Praktek Pengelolaan dan Pemusnahan Limbah Obat pada Sarana Pelayanan Farmasi Komunitas Wilayah Bandung Timur
}

\author{
Rizki Siti Nurfitria", Khoerul Rasyidin, Ni Nyoman Sri Mas Hartini, Ani Anggriani \\ Fakultas Farmasi Universitas Bhakti Kencana Bandung, Jawa Barat 40614, Indonesia \\ *Corresponding author: rizki.sitinurfitria@bku.ac.id
}

Info Artikel:Diterima 10 Desember 2021 ; Direvisi 29 Januari 2022 ; Disetujui 1 Februari 2022

Tersedia online : 17 Februari 2022 ; Diterbitkan secara teratur : Februari 2022

Cara sitasi (Vancouver): Nurfitria RS, Rasyidin K, Hartini NNSM, Anggriani A. Praktek Pengelolaan dan Pemusnahan Limbah Obat pada Sarana Pelayanan Farmasi Komunitas Wilayah Bandung Timur. Jurnal Kesehatan Lingkungan Indonesia [Online]. 2022 Feb;21(1):83-92. https://doi.org/10.14710/jkli.21.1.83-92.

\begin{abstract}
ABSTRAK
Latar belakang: Limbah farmasi sebagai salah satu penyebab pencemaran lingkungan masih menjadi masalah dilematis pada sarana pelayanan farmasi komunitas dimana obat harus dimusnahkan secara mandiri. Penelitian ini bertujuan untuk mengevaluasi kesesuaian pengelolaan dan pemusnahan limbah obat pada sarana farmasi komunitas wilayah Bandung Timur.

Metode: Penelitian ini merupakan studi deskriptif yang dilakukan melalui pengamatan langsung dan wawancara pada bulan April - September 2021. Responden merupakan penanggung jawab kegiatan pengelolaan dan pemusnahan limbah obat pada 47 sarana farmasi yang terdiri dari apotek dan klinik pratama yang ditentukan secara accidental sampling. Data diolah dan dianalisis secara kuantitatif dan kualitatif mencakup karakteristik limbah obat dan gambaran kesesuaian pengelolaan dan pemusnahan obat.

Hasil: Semua sarana hanya menghasilkan limbah obat golongan obat keras, obat OTC, obat tradisional dengan bentuk sediaan solid mendominasi sebanyak rerata 330,2 item (41,9 g). Kegiatan pemusnahan limbah obat dilakukan secara mandiri sebesar $85,7 \%$ sedangkan $13,3 \%$ penanganan dilakukan dengan cara diserahkan ke pihak lain. Sebagian besar sarana farmasi belum melakukan kerjasama dengan pihak ketiga. Sebesar 59,6\% sarana telah memiliki alur pengelolaan limbah yang sesuai sedangkan sebelas apotek dan tiga klinik pratama memiliki alur penanganan limbah obat yang tidak sesuai.

Simpulan: Separuh lebih sarana farmasi telah memiliki alur pengelolaan limbah sesuai Pedoman Pengelolaan Limbah Obat Rusak dan Kadaluarsa di Fasilitas Pelayanan Kesehatan tahun 2021 namun diperlukan sinkronisasi dengan pedoman layanan farmasi yang lain serta sosialisasi kepada pengelola. Apoteker sebagai pengelola perbekalan farmasi perlu mendapat daya dukung yang baik dalam menangani limbah obat secara professional.
\end{abstract}

Kata kunci: farmasi komunitas; limbah obat; pengelolaan

\section{ABSTRACT}

Title: Suitability of Practices for Management and Destruction of Drug Waste in Community Pharmacy Service Facilities in the East Bandung Region

Background: Pharmaceutical waste as one of the causes of environmental pollution is still a dilemma for community pharmacy service facilities where drugs must be destroyed independently. This study aimed to evaluate the suitability of the management and destruction of drug waste in community pharmacy facilities in the East Bandung area.

Method: This research was a descriptive study conducted through direct observation and interviews in AprilSeptember 2021. Respondents were responsible for the management and destruction of drug waste at 47 pharmaceutical facilities consisting of pharmacies and primary clinics determined by accidental sampling. The 
data was processed and analyzed quantitatively and qualitatively including the characteristics of drug waste and a description of the suitability of the management and destruction of drugs.

Result: All facilities only produce solid drug, OTC drugs, and traditional medicines waste with solid dosage forms dominating an average of 330.2 items $(41.9 \mathrm{~g}$ ). The activity of destroying drug waste is carried out independently by $85.7 \%$, while $13.3 \%$ of handling is carried out by handing it over to other parties. Most of the pharmaceutical facilities have not collaborated with third parties. As many as $59.6 \%$ of the facilities had appropriate waste management lines, while eleven pharmacies and three primary clinics had inappropriate drug waste management lines.

Conclusion: More than half of pharmaceutical facilities already have a waste management flow in accordance with the Guidelines for Waste Management of Damaged and Expired Drugs in Health Service Facilities in 2021, but synchronization with other pharmaceutical service guidelines and socialization to managers is required. Pharmacists as managers of pharmaceutical supplies need to have good support in dealing with drug waste in a professional manner.

Keywords: Community Pharmacy; Drug Waste; Management

\section{PENDAHULUAN}

Pencemaran lingkungan yang disebabkan oleh limbah farmasi menjadi perhatian global. Limbah farmasi merupakan salah satu jenis limbah medis yang terdapat di ekosistem dan berpotensi menimbulkan dampak yang merugikan. Sumber pencemaran yang signifikan dari limbah farmasi di lingkungan adalah pembuangan obat yang rusak dan kadaluarsa yang sebelumnya tidak dikelola atau dikelola dengan buruk. ${ }^{(1)}$ Selain itu, terdapat beberapa golongan obat rusak dan kadaluarsa yang dapat menimbulkan risiko kesehatan bagi masyarakat. ${ }^{(2,3)}$

Kegiatan pemusnahan obat merupakan salah satu standar pelayanan kefarmasian non-klinik yang wajib diterapkan di rumah sakit, puskesmas, dan apotek. Pemusnahan sediaan farmasi, alat kesehatan, dan bahan medis habis pakai yang tidak dapat digunakan lagi harus dilakukan dengan tata cara yang sesuai dengan ketentuan peraturan perundang-undangan yang berlaku. Apoteker sebagai pengelola di Instalasi Farmasi terkait bertanggung jawab atas pemusnahan obat. Namun, pengelolaan limbah farmasi dari fasilitas kesehatan masih memiliki banyak permasalahan. Lebih dari $50 \%$ pengelolaan perbekalan farmasi dan alat kesehatan dilakukan langsung oleh Apoteker, namun masih ada beberapa Apoteker yang tidak melaksanakan kegiatan yaitu sebesar $21,3 \%{ }^{(4)}$ Sebanyak $75 \%$ petugas fasilitas kesehatan dasar di Kota Yogyakarta memiliki tingkat pengetahuan yang tinggi tentang pengelolaan limbah obat, namun sebagian besar apoteker masih tidak tepat dalam memusnahkan obat. ${ }^{(5,6)}$ Kendala yang dihadapi berkisar pada belum tersosialisasinya dokumen rinci kebijakan atau petunjuk teknis pengelolaan limbah farmasi di unit kesehatan, sehingga kegiatan pengelolaan dan pemusnahan limbah farmasi belum terlaksana dengan baik. $^{(7,8)}$ Di India, praktik pengelolaan limbah obat dianggap tidak sesuai karena alasan peraturan yang tidak jelas, kurangnya kesadaran dan metode pengendalian yang tidak efektif. ${ }^{(9)}$

Terkait dengan pengelolaan limbah fasilitas pelayanan kesehatan, beberapa penelitian terkait pemusnahan obat telah dilakukan di rumah sakit. Penelitian sebelumnya menunjukkan bahwa pelayanan kesehatan dasar seperti Puskesmas belum memiliki kebijakan pengelolaan obat rusak/kadaluwarsa serta kegiatan penyimpanan dan pemusnahan obat masih belum baik. ${ }^{(3)}$ Namun, beberapa Puskesmas telah menerapkan sistem pengelolaan limbah obat sesuai Standar Pelayanan Kefarmasian (terakhir tercantum dalam Peraturan Menteri Kesehatan No. 72-74 Tahun 2016), sedangkan klinik belum menerapkan pengelolaan limbah obat mandiri sesuai standar. Untuk pengelolaan limbah obat klinik biasanya telah dilakukan oleh pihak ketiga seperti halnya rumah sakit. ${ }^{(10)}$ Di sisi lain, pandemi Covid-19 telah meningkatkan limbah medis dan non-medis termasuk pembuangan obat dan suplemen akibat peningkatan penggunaan obat sebagai upaya pencegahan penularan virus. ${ }^{(11)}$

Penelitian pengelolaan limbah obat banyak didominasi oleh kajian pengelolaan limbah medis secara umum di fasilitas kesehatan lanjutan yaitu rumah sakit. Namun penelitian serupa pada fasilitas farmasi dasar seperti apotek dan klinik pratama masih sangat jarang. Padahal, sarana tersebut sangat didorong untuk bisa memusnahkan obat secara mandiri. Peran apoteker sangat diperlukan dalam pengelolaan obat di apotek untuk mencegah kerusakan obat dan meminimalkan kerugian akibat obat rusak dan obat kadaluarsa. ${ }^{(12)}$ Oleh karena itu, penelitian ini akan fokus untuk mendapatkan tinjauan yang lengkap tentang pengelolaan limbah farmasi khususnya pemusnahan obat rusak dan kadaluarsa di apotek dan klinik pratama. Penelitian ini bertujuan untuk memperoleh gambaran pengelolaan dan pemusnahan limbah obat serta mengevaluasi kesesuaian alur penanganan limbah obat di apotek dan klinik pratama di wilayah Bandung Timur.

\section{MATERI DAN METODE}

Penelitian ini merupakan studi deskriptif dengan desain cross-sectional yang dilakukan melalui pengamatan langsung dan wawancara. Populasi pada 
penelitian ini adalah petugas penanggung jawab kegiatan pengelolaan dan pemusnahan obat pada seluruh sarana apotek dan klinik pratama yang berada di wilayah Bandung Timur yang berjumlah 234 sarana. Sampel responden ditentukan sebanyak 37 petugas apotek dan 10 petugas klinik pratama yang dihitung dengan teknik accidental sampling. Jumlah ini tidak mencakup apotek dan klinik yang termasuk ke dalam jenis usaha waralaba (franchise) dengan pertimbangan usaha tersebut biasanya telah memiliki system manajemen yang baik sehingga kemungkinan memiliki system pengelolaan dan pembuangan limbah farmasi yang sudah terintegrasi. Objek kajian dari penelitian ini adalah kegiatan pengelolaan dan pemusnahan limbah obat yang terdiri dari obat rusak dan obat kadaluarsa yang terdapat di sarana apotek dan klinik pratama. Data konkuren dikumpulkan melalui pengamatan secara langsung kegiatan pengelolaan dan pemusnahan limbah obat rusak dan kadaluarsa yang pada saat tersebut dikumpulkan dan disimpan untuk kemudian dimusnahkan setelah periode tertentu. Variabel dalam penelitian ini yaitu karakteristik limbah obat, metode pemusnahan, titik akhir pengelolaan, alur pengelolaan, frekuensi pemusnahan, kerjasama pihak ketiga, dan biaya pengelolaan limbah obat yang dianalisis secara deskriptif dan disajikan secara naratif. Kesesuaian praktek pengelolaan dan pemusnahan obat dievaluasi berdasarkan Pedoman Pengelolaan Limbah Obat Rusak dan Kadaluarsa di Fasilitas Pelayanan Kesehatan tahun 2021 sebagai acuan terbaru. Etik penelitian mencakup confidentiality dan anonamity. Peneliti meminta izin kepada sarana terkait sebagai subjek yang diteliti dimana data yang diambil dalam penelitian ini bersifat anonym (rahasia). Nama responden dan tempat penelitian dirahasiakan dalam segala bentuk penulisan hasil penelitian.

\section{HASIL DAN PEMBAHASAN}

Pada bagian ini akan dipaparkan hasil penelitian untuk menjawab tujuan penelitian. Hasil yang akan diolah dan dianalisis meliputi karakteristik responden, karakteristik limbah obat, deskripsi pengelolaan dan pemusnahan obat, kesesuaian metode, titik akhir kegiatan pengelolaan dan pemusnahan limbah obat serta kebijakan, kendala dan peran apoteker dalam pengelolaan dan pemusnahan limbah obat.

\section{Karakteristik Responden}

Karakteristik petugas pengelolaan limbah obat yang meliputi jenis kelamin, usia, jabatan, lama praktik, dan jumlah jam praktik per minggu disajikan pada Tabel 1 di bawah ini. Petugas pengelola limbah obat bertanggung jawab atas pemusnahan obat dan menjadi responden wawancara dalam penelitian ini.

Tabel 1. Karakteristik Responden Pada Sarana Apotek dan Klinik Pratama Wilayah Bandung Timur Tahun 2021

\begin{tabular}{lccc}
\hline \multirow{2}{*}{ Karakteristik } & Gabungan & Apotek & Klinik Pratama \\
\cline { 2 - 4 } Jenis Kelamin & \multicolumn{3}{c}{ F (\%) } \\
$\quad$ Pria & $7(15,5)$ & $5(14,2)$ & $2(16,7)$ \\
$\quad$ Wanita & $40(84,1)$ & $32(85,2)$ & $8(83,3)$ \\
Usia (tahun) & & & \\
$\quad<30$ & $2(4,3)$ & $0(0)$ & $2(16,7)$ \\
$30-40$ & $16(34,0)$ & $11(29,7)$ & $5(50,0)$ \\
$41-50$ & $24(51,1)$ & $21(56,8)$ & $3(33,3)$ \\
$>50$ & $5(10,6)$ & $5(13,5)$ & $0(0)$ \\
Jabatan & & & \\
$\quad$ Apoteker Penanggung & $29(61,7)$ & $22(59,5)$ & $7(66,7)$ \\
Jawab & $5(10,6)$ & $5(13,5)$ & $0(0)$ \\
$\quad$ Asisten Apoteker & $13(27,7)$ & $10(27,0)$ & $3(33,3)$ \\
$\quad$ Manager Klinik & & & \\
Pengalaman kerja (tahun) & $5(10,6)$ & $5(13,5)$ & $0(0)$ \\
$1-2$ & $7(14,9)$ & $5(13,5)$ & $2(16,7)$ \\
$3-4$ & $34(72,3)$ & $26(70,3)$ & $8(83,3)$ \\
$>4$ & & & \\
Jumlah jam praktek (/minggu) & $3(33,3)$ \\
$\quad<30$ & $8(17,0)$ & $5(13,5)$ & $3(33,3)$ \\
$30-40$ & $8(17,0)$ & $5(13,5)$ & $3(33,3)$ \\
$41-50$ & $24(51,1)$ & $21(56,8)$ & $0(0)$ \\
$>50$ & $5(10,6)$ & $5(13,5)$ & $10(100)$ \\
\hline Total & $47(100)$ & $37(100)$ & \\
\hline
\end{tabular}

\section{Karakteristik Limbah Obat}

Ada dua macam limbah obat yang harus dimusnahkan di semua sarana farmasi, yaitu obat rusak dan obat kadaluarsa. Obat rusak adalah obat- obat yang sudah tidak dikenali lagi karena labelnya sudah rusak. Obat tersebut bisa saja disalahgunakan kembali sehingga dapat menimbulkan bahaya dan menimbulkan resiko kesehatan pada beberapa 
golongan obat. Sedangkan obat kadaluarsa adalah obat yang telah melewati masa gunanya. Kekuatan dan kadar obat tersebut sudah menurun lebih kecil dari yang dipersyaratkan oleh Farmakope sehingga efektivitasnya berkurang. Terkadang obat yang kadaluarsa sudah mengalami penguraian dimana hasil urainya dapat membahayakan kesehatan dan jiwa manusia yang mengkonsumsinya. ${ }^{(13)}$ Semua obat yang telah rusak atau kadaluarsa di apotek maupun klinik pratama harus segera dimusnahkan agar tidak membahayakan bagi pasien maupun lingkungan sekitar. ${ }^{(14)}$ Limbah obat dikelompokkan berdasarkan logo atau penandaan, kelas terapi, bentuk sediaan, jenis sediaan, dan jenis kemasan yang dihasilkan seperti terlihat pada Tabel 2 berikut.

Tabel 2. Karakteristik Limbah Obat di Apotik dan Klinik Pratama Wilayah Bandung Timur Tahun 2021

\begin{tabular}{|c|c|c|}
\hline $\begin{array}{c}\text { Karakteristik } \\
\end{array}$ & $\mathbf{F}(\%)$ & Jumlah rata-rata \\
\hline Penggolongan menurut & & (item) \\
\hline Undang-Undang & & (1tem) \\
\hline Obat Keras & $47(100)$ & 4,1 \\
\hline Obat Bebas Terbatas (OTC) & $22(46,8)$ & 0,8 \\
\hline Obat Bebas (OTC) & $40(85,1)$ & 1,9 \\
\hline Obat Tradisional & $22(46,8)$ & 0,8 \\
\hline Kelas Terapi & & (item) \\
\hline Antibiotik/Antiinfeksi & $22(46,8)$ & 0,8 \\
\hline Antineoplastik & $0(0)$ & 0 \\
\hline Lainnya & $22(46,8)$ & 1,4 \\
\hline Bentuk Sediaan & & (item) \\
\hline Tablet & $47(100)$ & 330,2 \\
\hline Sirup & $40(85,1)$ & 5,1 \\
\hline Drop & $7(14,9)$ & 0,2 \\
\hline Salep/Krim & $11(23,4)$ & 1 \\
\hline Injeksi & $4(8,5)$ & 0,2 \\
\hline \multicolumn{3}{|l|}{ Jenis Sediaan } \\
\hline Padat & $47(100)$ & $41,9(\mathrm{~g})$ \\
\hline Semi padat & $7(14,9)$ & $8,5(\mathrm{~g})$ \\
\hline Cair & $40(85,1)$ & $419,2(\mathrm{ml})$ \\
\hline \multicolumn{3}{|l|}{ Jenis Kemasan } \\
\hline Primer & $47(100)$ & $6,4 \mathrm{~kg}$ \\
\hline Sekunder & $47(100)$ & $10,5 \mathrm{~kg}$ \\
\hline Tersier & $47(100)$ & $3,7 \mathrm{~kg}$ \\
\hline Jumlah Kerugian & & $(\operatorname{Item}(\%))$ \\
\hline Jumıan Kerugian & & $($ Rp. $(\%))$ \\
\hline Obat rusak & $4(8,5)$ & $\begin{array}{c}\text { Tidak diketahui }(0) \\
20.769(0,4)\end{array}$ \\
\hline Obat Kadaluarsa & $47(100)$ & $\begin{array}{c}\text { Tidak diketahui }(1,6) \\
794.741(14,1)\end{array}$ \\
\hline
\end{tabular}
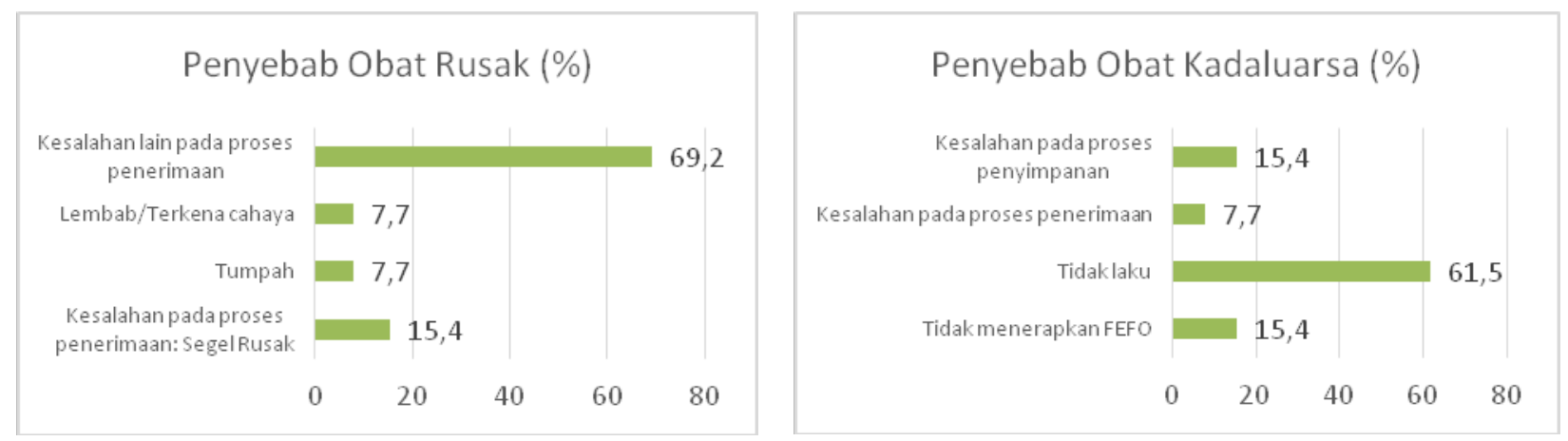

Gambar 1. Penyebab Obat Rusak dan Kadaluarsa Di Apotik Dan Klinik Pratama Wilayah Bandung Timur Tahun 2021 
Pada Gambar 1 dapat terlihat bahwa sebagian besar penyebab obat rusak belum diketahui pasti namun sebagian besar terjadi karena kesalahan pada proses penyimpanan. Sedangkan penyebab obat kadaluarsa sebagian besar karena tidak laku.

\section{Gambaran Pemusnahan Obat}

Kegiatan pemusnahan limbah obat di apotek sebagian besar dilakukan secara mandiri oleh petugas dengan persentase 85,7 \%. Sebesar 13,3 \% penanganan dilakukan dengan cara diserahkan ke pihak lain diantaranya dititipkan ke Puskesmas terdekat untuk dilakukan pemusnahan. Sebagian dari klinik pratama melakukan pemusnahan sendiri dan sebagian lagi menyerahkan ke pihak ketiga dengan persentase masing-masing $50 \%$ seperti terlihat pada Tabel 3 dan Gambar 2.

Tabel 3. Profil dan Kesesuaian Penanganan Limbah Obat Apotek dan Klinik Pratama di Wilayah Bandung Timur Tahun 2021

\begin{tabular}{|c|c|c|c|c|c|c|}
\hline \multirow[b]{2}{*}{ Variabel } & \multicolumn{2}{|c|}{ Gabungan $(n=47)$} & \multicolumn{2}{|c|}{ Apotek (n=37) } & \multicolumn{2}{|c|}{ Klinik Pratama $(n=10)$} \\
\hline & $\mathbf{F}(\%)$ & $\begin{array}{c}\text { Kesesuaian, } \\
\text { F(\%) }\end{array}$ & $\mathbf{F}(\%)$ & $\begin{array}{c}\text { Kesesuaian, } \\
\text { F(\%) }\end{array}$ & $\mathbf{F}(\%)$ & $\begin{array}{c}\text { Kesesuaian, } \\
\text { F(\%) }\end{array}$ \\
\hline \multicolumn{7}{|l|}{ Metode } \\
\hline Dibakar/Insinerasi & $10(21,4)$ & \multirow{4}{*}{$28(59,6)$} & $5(13,5)$ & \multirow{4}{*}{$21(56,8)$} & $5(50)$ & \\
\hline Dikubur & $13(27,8)$ & & $11(29,7)$ & & $2(20,0)$ & \\
\hline Dibuang ke TPA* & $6(12,8)$ & & $5(13,5)$ & & $1(10,0)$ & $7(70,0)$ \\
\hline Dibuang ke saluran air & $18(38,5)$ & & $16(43,2)$ & & $2(20,0)$ & \\
\hline \multicolumn{7}{|l|}{ Titik Akhir } \\
\hline Penyimpanan & $3(6,41)$ & \multirow{6}{*}{$28(59,6)$} & $0(0)$ & \multirow{6}{*}{$21(56,8)$} & $3(30,0)$ & \multirow{6}{*}{$7(70,0)$} \\
\hline TPA & $5(10,7)$ & & $5(13,5)$ & & $0(0)$ & \\
\hline Saluran air & $18(38,5)$ & & $16(43,2)$ & & $2(20,0)$ & \\
\hline Insinerator & $5(10,7)$ & & $0(0)$ & & $5(50)$ & \\
\hline Tanah Kosong & $11(23,5)$ & & $11(29,7)$ & & $0(0)$ & \\
\hline Lainnya & $5(10,7)$ & & $5(13,5)$ & & $0(0)$ & \\
\hline \multicolumn{7}{|l|}{ Alur Penanganan Limbah } \\
\hline $\begin{array}{l}\text { Pemisahan-Penyimpanan- } \\
\text { Pemusnahan mandiri }\end{array}$ & $32(68,4)$ & \multirow[t]{2}{*}{$28(59,6)$} & $32(86,5)$ & \multirow[t]{2}{*}{$21(56,8)$} & $0(0)$ & \multirow[t]{2}{*}{$7(70,0)$} \\
\hline $\begin{array}{l}\text { Penyimpanan-Penyerahan } \\
\text { ke Pihak Ketiga }\end{array}$ & $7(70,0)$ & & $0(0)$ & & $7(70,0)$ & \\
\hline
\end{tabular}

*TPA= Tempat Pembuangan Akhir
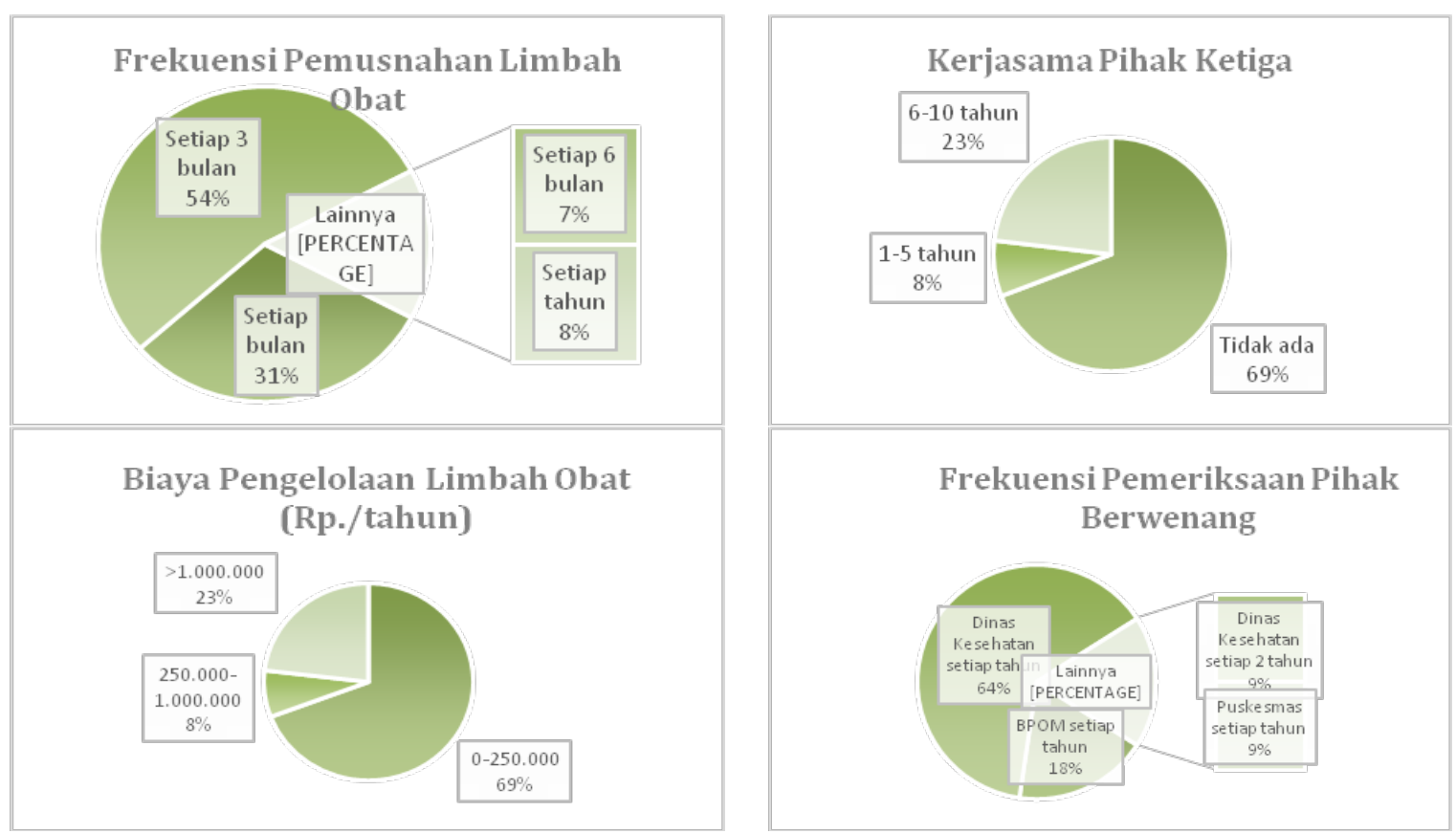

Gambar 2. Frekuensi Pemusnahan, Biaya Penanganan Limbah, Kerjasama Dengan Pihak Ketiga, dan Pemeriksaan oleh Pihak Berwenang di Apotik dan Klinik Pratama Wilayah Bandung Timur Tahun 2021 
Dari Tabel 1 di atas terlihat bahwa sebagian besar pengelola limbah obat di apotek dan klinik telah bekerja lebih dari empat tahun sehingga memiliki pengalaman kerja yang lama di bidang kesehatan dan dianggap memiliki keahlian khusus dalam hal pemusnahan obat. Berdasarkan hasil penelitian sebelumnya, petugas fasilitas kesehatan dasar memiliki sikap yang positif terhadap pengelolaan limbah obat rusak dan kadaluarsa. ${ }^{(5)}$ Beberapa responden merupakan asisten apoteker yang terlibat langsung dalam pengelolaan dan pemusnahan limbah obat. Hal ini menunjukkan bahwa apoteker penanggung jawab apotek tidak selalu hadir selama jam pelayanan. Hal ini terlihat dari jumlah jam praktik per minggu yang tidak memenuhi persyaratan di beberapa fasilitas.

Tabel 2 menunjukan bahwa 47 sarana hanya menghasilkan limbah obat golongan obat keras, OTC, obat tradisional dan tidak menghasilkan limbah obat golongan Narkotika, Psikotropika, dan Antineoplastik. Antineoplastik yang merupakan kelompok obat kanker harus disimpan terpisah dari kelompok obat lain, dikemas dengan aman pada kontainer atau wadah. Limbah obat ini lebih baik jika dikembalikan ke produsen untuk dibuang. Jika opsi ini tidak bisa dilakukan, maka harus dihancurkan di insinerator yang beroperasi pada suhu tinggi di atas $1200^{\circ} \mathrm{C}$. Limbah antineoplastik tidak boleh dibuang ke saluran air atau landfill kecuali telah melewati proses encapsulation atau inertisasi. Jenis limbah farmasi jenis ini hanya dapat dibuang ke sistem saluran pembuangan setelah terjadi degradasi kimiawi dan tidak dapat dibuang tanpa pengolahan sebelumnya. Khusus obat anti-infeksi tidak boleh dibuang dalam bentuk yang belum diolah, karena obat tersebut tidak stabil, dan pemusnahannya paling efektif dengan cara dibakar. Jika encapsulation atau inertisasi tidak dapat dilakukan obat antiinfeksi cair dapat dilarutkan dalam air didiamkan selama dua minggu, kemudian dibuang ke saluran pembuangan air limbah. ${ }^{(13)}$

Bentuk sediaan tablet yang merupakan sediaan solid mendominasi limbah obat dengan jumlah ratarata 330,2 item (41,9 g). Hal ini sejalan dengan penelitian Fabima (2018), Dewi, dkk. (2021), dan Kareri (2018) dimana proporsi tablet kadaluarsa di beberapa sarana kesehatan dasar cukup tinggi, menunjukkan bahwa pengelolaan limbah farmasi bentuk sediaan ini perlu diperhatikan agar tidak mencemari lingkungan dan terhindar dari penyalahgunaan obat. ${ }^{(5,15,16)}$ Pemusnahan limbah obat juga seringkali melibatkan kemasannya. Limbah kemasan primer yang dihasilkan meliputi blister, strip, dan botol. Limbah kemasan primer sediaan padat biasanya dipisahkan setelah obatnya dikeluarkan, sedangkan limbah kemasan primer sediaan semipadat atau cair harus dimusnahkan bersamaan dengan sediaan. Belum ada pedoman teknis yang jelas bagaimana membuang limbah kemasan ini karena meskipun tampak seperti limbah anorganik namun tetap bisa terjadi kontaminasi. Limbah kemasan sekunder yang dihasilkan berupa kotak karton obat sedangkan limbah kemasan tersier yang dihasilkan berupa kardus. Sebagian besar apotek dan klinik menghasilkan kemasan sekunder $>10 \mathrm{~kg}$. Limbah kemasan sekunder dan tertier obat adalah jenis limbah non-medis anorganik yang bisa dipilah dan dikumpulkan serta menjadi sumber pemasukan sarana melalui skema penyerahan ke bank sampah atau pengepul.

Besar kerugian akibat obat rusak bervariasi dan nilainya bisa sangat besar pada kelompok obat kadaluarsa. Hal ini sejalan dengan hasil penelitian Syahreni dkk. (2016) yang menyatakan obat kadaluarsa dapat menyebabkan kerugian finansial yang cukup besar karena tidak bisa atau sulit dikembalikan ke supplier atau diperjualbelikan. ${ }^{(12)}$ Semakin banyak obat rusak dan kadaluarsa yang dihasilkan di apotek dan klinik maka semakin tinggi kerugian yang dihasilkan. Sebagian besar apotek dan klinik mengalami kerugian finansial diakibatkan obat keras karena banyaknya permintaan dari dokter spesialis namun tidak tersalurkan sedangkan harganya relatif tinggi.. Maka perlu peningkatan manajemen pengelolaan obat agar dapat meminimalisir jumlah kerugian ekonomi akibat limbah obat.

Jumlah obat rusak dibandingkan jumlah total obat di apotek dan klinik sangat kecil sekali dan sangat jarang terjadi. Sedangkan perbandingan nilai obat rusak dari total nilai persediaan rata-rata $0,4 \%$. Jumlah obat kadaluarsa dibandingkan jumlah total obat rata-rata $1,6 \%$. Sedangkan perbandingan nilai obat kadaluarsa dari total nilai persediaan rata-rata $14,1 \%$. Hal ini sejalan dengan penelitian Nuraini (2013), Syahreni dkk. (2016), dan Dyahariesti dkk. (2019) dimana proporsi limbah obat kadaluarsa sangat beragam antara $0-0,5 \% .^{(12,17,18)}$ Pudjaningsih (2011) dalam Syahreni dkk. (2016) menyatakan bahwa persentase obat rusak dan kedaluarsa idealnya adalah nol persen, namun persentase maksimal obat rusak dan kadaluarsa adalah $0,20 \%$, dimana nilai ini dianggap sangat efektif tapi harus tetap di kontrol oleh apoteker maupun petugas yang ada agar tidak melebihi batas maksimal. ${ }^{(12)}$ Keempat nilai ini melebihi standar $0,20 \%$ yang artinya pengelolaan obat kadaluarsa pada indikator ini belum efektif. Oleh karena itu, diperlukan peningkatan manajemen pelayanan dan sistem pengarsipan apotek yang lebih baik. ${ }^{(14,18)}$

Adanya kejadian obat rusak karena sediaan tumpah atau sediaan lembab/terkena cahaya menunjukkan bahwa penyimpanan obat harus dilakukan dengan memperhatikan keamanan dan sesuai syarat farmasi. Hal ini sejalan dengan penelitian Syahreni dkk. (2016) dimana penyebab obat rusak sebagian besar karena kesalahan pada proses penyimpanan. Jika ditemukan obat rusak pada saat penerimaan barang, maka dapat segera dikembalikan (retur) ke Pedagang Besar Farmasi sehingga apotek maupun klinik tidak mengalami kerugian. Namun hal ini tidak selalu dapat dilakukan 
karena bergantung pada kebijakan supplier. ${ }^{(12)}$ Timbulnya obat kadaluarsa menunjukan siklus manajemen obat tidak berjalan dengan baik sehingga perlu pemantauan secara berkala. Hal ini sejalan dengan penelitian Syahreni dkk. (2016) dan Mardiana (2017) dimana obat kadaluarsa disebabkan karena tidak laku atau sistem distribusi tidak baik. ${ }^{(12,19)}$ Metode First Expired First Out dapat dilakukan untuk mengelola obat-obatan sesuai expired date. Diperlukan perencanaan dan pengendalian obat yang lebih baik untuk menganalisis kelompok obat slow moving, fast moving dan mengantisipasi kejadian dead moving (stok mati).

Dari Tabel 3 di atas sebanyak 21,4 \% sarana menggunakan metode pembakaran dalam memusnahkan limbah obat terdiri dari apotek dimana obat dikumpulkan, fasa padat dipisahkan dari fasa cair lalu dibakar. Berbeda dengan klinik, obat dibakar dengan bantuan pihak ketiga menggunakan Incenerator. Hal ini sejalan dengan penelitian Jovanovic, et al. (2016) bahwa fasilitas kesehatan yang memiliki lingkup pelayanan lebih besar dan membuang limbah dalam jumlah yang lebih banyak biasanya memiliki sistem pemilahan limbah farmasi yang lebih berkembang. ${ }^{(10)}$ Fasa cair obat dapat dibuang melalui saluran air seperti wastafel atau WC menurut Pedoman Pengelolaan Limbah Obat Rusak dan Kadaluarsa tahun 2021 namun menurut WHO obat padat atau yang terkonsentrasi dalam cairan harus terlebih dahulu dilarutkan dengan air secukupnya selama beberapa minggu lalu dibuang ke saluran air yang besar dan limbah cair farmasi yang diencerkan atau tidak diencerkan tidak boleh dimasukkan ke dalam air permukaan yang bergerak lambat atau tergenang. ${ }^{(13,20)}$ Metode dikubur walaupun pada lahan kosong tidak dianjurkan pada kedua pedoman ini namun ternyata hal tersebut masih banyak dilakukan berdasarkan data di atas sebesar $27,8 \%$

Tahap pemisahan menjadi masalah utama dalam alur pengelolaan limbah obat di klinik karena di fasilitas ini terdapat potensi yang besar untuk bercampurnya limbah medis dan non medis, terutama yang melibatkan alat kesehatan menular dan Perbekalan Kesehatan Rumah Tangga. Hal ini sejalan dengan penelitian Arisma (2021) yang menyatakan pada sarana pelayanan yang lebih kompleks terdapat limbah padat medis yang bercampur dengan limbah non medis. ${ }^{(21)}$ Sebesar 59,6\% sarana telah memiliki alur pengelolaan limbah sesuai pedoman Pedoman Pengelolaan Limbah Obat Rusak dan Kadaluarsa tahun 2021. Sedangkan 11 apotek dan tiga klinik pratama memiliki alur pengelolaan obat yang tidak sesuai. Masih terdapat apotek yang tidak melakukan kegiatan pemusnahan limbah obat sesuai peraturan (limbah obat dibuang di tempat pembuangan akhir) dan klinik pratama yang belum mengelola limbah obat sesuai peraturan dan belum bekerjasama dengan pihak ketiga (limbah obat dibuang dengan penguburan atau ke tempat pembuangan sampah). Pedoman yang umum diketahui oleh pengelola, yaitu Peraturan Menteri Kesehatan No. 72 dan 73 Tahun 2016 tentang Standar Pelayanan Kefarmasian di Rumah Sakit dan Apotek serta Petunjuk Teknis Standar Pelayanan Farmasi di Apotek dan Rumah Sakit tahun 2019 (klinik masih mengacu pada standar pelayanan kefarmasian rumah sakit) dan Praktik Kefarmasian yang Baik (GPP) tahun 2011. Kesesuaian pengelolaan limbah farmasi dapat mengurangi risiko terhadap lingkungan dan meningkatkan kesehatan masyarakat. ${ }^{(7)}$

Berdasarkan Gambar 2 di atas, sebanyak 54\% sarana melakukan pemusnahan obat setiap tiga bulan sekali. Pada sarana klinik yang sudah bekerjasama dengan pihak ketiga, pengangkutan limbah obat setiap tiga bulan merupakan paket dengan biaya paling rendah. Namun sebagian besar apotek dan separuh klinik pratama ternyata belum melakukan kerjasama dengan pihak ketiga. Kebanyakan dari apotek beranggapan bahwa biaya yang akan dikeluarkan untuk bekerjasama dengan perusahaan pengelolaan limbah cukup besar. Sebesar 10,7\% sarana yang sudah bekerja sama dengan pihak ketiga merupakan klinik pratama yang sudah cukup lama menyerahkan pengelolaan limbah obat kepada perusahaan pengelolaan limbah medis. Pasal 59 UU Nomor 32 Tahun 2009 tentang Perlindungan dan Pengelolaan Lingkungan Hidup menyatakan bahwa "setiap orang yang menghasilkan limbah B3 wajib melakukan pengelolaan limbah yang dihasilkannya dan dalam hal setiap orang tidak mampu melakukan sendiri pengelolaan limbah, pengelolaannya diserahkan kepada pihak lain".

Biaya pengelolaan limbah yaitu sejumlah biaya yang dikeluarkan dalam melaksanakan pengelolaan obat rusak dan kadaluarsa di apotek dan klinik. ${ }^{(2)}$ Biaya yang dikeluarkan untuk melakukan kegiatan pengelolaan dan pemusnahan limbah obat secara mandiri umumnya bernilai di bawah Rp. 1.000.000,sedangkan sarana yang mengeluarkan untuk biaya lebih besar dari Rp. 1.000.000,- adalah klinik yang sudah melakukan MoU dengan pihak ketiga (berdasarkan hasil wawancara yaitu berkisar Rp. 1.500.000,-). Dari gambaran di atas dapat terlihat bahwa apotek dan klinik pratama dapat mempertimbangkan kerjasama dengan suatu perusahaan pengelola limbah medis yang memiliki beragam harga paket penjemputan limbah.

Inspeksi teknis pengelolaan obat pada sarana farmasi termasuk pemusnahan obat biasanya dilakukan oleh Balai atau Balai Besar Pengawasan Obat dan Makanan dengan cara sampling acak, sedangkan kelayakan sarana prasarana farmasi biasanya dilakukan oleh Dinas Kesehatan. Menurut responden, inspeksi pemeriksaan kegiatan penyimpanan dan pemusnahan limbah obat paling banyak dilakukan oleh Dinas Kesehatan setempat (terkadang ada juga perwakilannya yang berasal dari Puskesmas yang berkunjung ke sarana). 


\section{Kebijakan, Kendala dan Peran Apoteker}

Sebagian besar apotek dalam penanganan limbah obat mengacu pada Peraturan Menteri Kesehatan Nomor 73 Tahun 2016 Tentang Standar Pelayanan Kefarmasian di Apotek (yang telah dilengkapi dengan Petunjuk Teknis Standar Pelayanan Farmasi di Apotek tahun 2019). Sedangkan banyak petugas di klinik berpegang pada surat perjanjian Kerjasama dengan pihak ketiga (namun tidak mengetahui peraturan yang mendasarinya). Dikatakan juga bahwa isu pengumpulan dan penyimpanan limbah obat yang bercampur dengan dengan limbah B3 lainnya belum tersosialisasi secara jelas oleh pemerintah. Pada saat pengumpulan data penelitian ini berlangsung, Kementerian Kesehatan RI mengeluarkan Pedoman Pengelolaan Obat Rusak dan Kedaluwarsa di Fasilitas Pelayanan Kesehatan dan Rumah Tangga tahun 2021. (20) Pengelolaan limbah medis fasyankes secara teknis telah diatur dalam Peraturan Menteri Lingkungan Hidup dan Kehutanan yang mengatur mengenai Tata Cara dan Persyaratan Teknis Pengelolaan Limbah Bahan Berbahaya dan Beracun dari Fasilitas Pelayanan Kesehatan. Diharapkan pedoman ini dapat menjadi referensi yang secara teknis memberikan pedoman terkait pengelolaan limbah farmasi termasuk obat rusak dan kedaluwarsa di fasyankes dan rumah tangga.

Pengelola perbekalan farmasi terutama apoteker pada sarana pelayanan dihadapkan dengan dilema harus melaksanakan penanganan limbah obat sesuai peraturan perundang-undangan yang berlaku tetapi dalam pelaksanaannya sarana fasilitas kesehatan sering tidak memiliki sumber daya atau keahlian untuk mencapai hal ini secara mandiri terutama pengendaliannya atas kesehatan lingkungan. ${ }^{(7)}$ Beberapa petugas belum menganggarkan secara khusus biaya penanganan limbah karena belum mempertimbangkan rasio efektivitas biaya kerjasama dengan pihak ketiga (limbah obat yang dihasilkan dinilai sedikit). Kurangnya sosialisasi dan edukasi dari Pemerintah terkait pengelolaan limbah obat juga masih menjadi kendala utama. Beberapa klinik mengeluhkan mengenai kurangnya agen pihak ketiga sehingga pada pelaksanaannya harus mengantri.

Peran apoteker dalam pengelolaan limbah obat di apotek dari sudut pandang responden yaitu memberikan arahan dalam hal pencatatan, pelaporan sampai dengan pemusnahan obat rusak dan kadaluarsa. Sedangkan peran apoteker di klinik yaitu memastikan proses pengelolaan limbah obat dilakukan dengan baik dan benar supaya tidak menkontaminasi lingkungan sekitar dan mencegah penyalahgunaan obat rusak dan kadaluarsa. Pada dasarnnya, apoteker memiliki potensi untuk memainkan peran yang lebih besar dalam pembuangan limbah farmasi yang bertanggung jawab terhadap lingkungan. ${ }^{(2)}$ Apoteker juga memiliki kewajiban meminimalisir kerusakan obat dan membatasi kerugian akibat obat kadaluarsa. ${ }^{(12)}$ Mereka berperan dalam membuat model praktik farmasi terintegrasi yang komprehensif untuk meningkatkan perawatan pasien dan meningkatkan kepuasan kerja sarana farmasi dengan mengumpulkan limbah obat dari masyarakat. ${ }^{(23)}$ Apoteker memiliki peran untuk memberikan konseling kepada masyarakat mengenai pembuangan obat yang yang baik dan benar. Di Amerika sekitar $30 \%$ pasien menerima konseling dari Apoteker tentang pembuangan obat. Kesadaran pasien terhadap cara pembuangan obat atau limbah farmasi dengan baik dan benar akan mempromosikan kesehatan bagi masyarakat dan lingkungan sekitar $(24,25)$. Hal ini bermanfaat agar citra profesi dianggap sebagai bagian integral dari tim perawatan kesehatan yang lebih luas untuk mencapai salah satu tujuan Sustainable Development Goals (SDGs) yaitu untuk melestarikan lingkungan dan keanekaragaman hayati. $(3,26)$

\section{SIMPULAN}

Dari hasil pengkajian di atas, dapat disimpulkan bahwa sebagian besar kegiatan pemusnahan limbah obat pada sarana pelayanan farmasi komunitas masih dilakukan secara mandiri dan belum melakukan kerjasama dengan pihak ketiga. Proporsi limbah obat rusak dan kadaluarsa pada sarana pelayanan farmasi komunitas dinilai belum sesuai syarat karenanya perlu peningkatan sistem pengarsipan apotek yang lebih baik. Separuh lebih sarana farmasi telah memiliki alur pengelolaan limbah sesuai Pedoman Pengelolaan Limbah Obat Rusak dan Kadaluarsa di Fasilitas Pelayanan Kesehatan tahun 2021 sebagai acuan terbaru namun diperlukan sinkronisasi dengan pedoman layanan farmasi yang lain serta sosialisasi kepada pengelola agar penerapan pengelolaan limbah obat dapat dipraktekkan dengan baik oleh petugas. Apoteker sebagai pengelola perbekalan farmasi perlu mendapat daya dukung yang memadai dalam menangani limbah obat secara professional. Pemerintah dan pihak berwenang perlu meningkatkan sosialisasi dan edukasi mengenai pengelolaan limbah obat serta memperluas kolaborasi dengan pihak ketiga. Apoteker, dengan komitmen profesionalnya terhadap kualitas penggunaan obat dan peran aktifnya terkait pengelolaan obat memainkan peran penting dalam penggunaan obat-obatan secara berkelanjutan dan juga memiliki peranan dalam perawatan pasien untuk menjaga kestabilan system kesehatan.

\section{UCAPAN TERIMA KASIH}

Tim Peneliti mengucapkan terima kasih kepada Kementerian Riset dan Teknologi/Badan Riset dan Inovasi Nasional tahun 2021 selaku pemberi dana hibah penelitian, Lembaga Penelitian dan Pengabdian Masyarakat Universitas Bhakti Kencana selaku fasilitator dan dosen praktisi serta mahasiswa yang telah memberikan masukan maupun terlibat di dalam diskusi riset ini. 


\section{DAFTAR PUSTAKA}

1. Amster ED. Mitigating pharmaceutical waste exposures: Policy and program considerations. Isr J Health Policy Res [Internet]. 2016;5(1):1-4. Available from: http://dx.doi.org/10.1186/s13584-016-0118-z

2. Singleton JA, Barter N, Nissen LM, McIntosh M. The Global Public Health Issue of Pharmaceutical Waste: What Role for Pharmacists? The Negative Impact of Pharmaceuticals on the Environment. J Glob Responsib [Internet]. 2014;5(1):126-37. Available from: https://www.emerald.com/insight/content/doi/10. 1108/JGR-03-2014-0009/full/html

3. Nuryeti Y, Ilyas Y. Pengelolaan Obat Kedaluwarsa dalam Upaya Pengendalian Pencemaran Lingkungan di Puskesmas Wilayah Kerja Kota Serang. Hig J Kesehat Lingkung [Internet]. 2018;4(3):138-42. Available from: http://journal.uin-

alauddin.ac.id/index.php/higiene/article/view/62 65

4. Diana K, Tandah MR, Basuki M. Pelaksanaan Standar Pelayanan Kefarmasian Di Apotek Kota Palu. J Ilm As-Syifaa [Internet]. 2019;11(1):4554. https://doi.org/10.33096/ja.v11i1.504

5. Fabima F, Aziz A, Juliani A, Indonesia UI. Evaluasi Pengelolaan Limbah Obat Di Fasilitas Kesehatan Dasar Di Kota Yogyakarta Evaluation of Drug Waste Management In Basic Health Facilites At Yogyakarta city [Internet]. Yogyakarta; 2018. Available from: https://dspace.uii.ac.id/bitstream/handle/1234567 $89 / 12414 / 08$ publikasi.pdf? sequence $=14 \&$ is Allowed $=y$

6. Pramestutie HR, Illahi RK, Hariadini AL, Ebtavanny TG, Savira M. Pengetahuan dan Ketepatan Apoteker dalam Pemusnahan Obat Sisa, Obat Rusak dan Obat Kedaluarsa. J Farm dan Ilmu Kefarmasian Indones [Internet]. 2021;8(3):250-8.

https://doi.org/10.20473/jfiki.v8i32021.250-258

7. Bruno J, Eaton S, Hemingway J, Towle E. Pharmaceutical Waste Disposal: Current Practices in Tirana, Albania [Internet]. Albania; 2016. Available from: https://core.ac.uk/download/pdf/212981746.pdf

8. Widiasih ES, Zahrulfa A, Rustamaji R, Suryawati S. Analisis dasar hukum, kebijakan dan peraturan penghapusan obat rusak dan kadaluwarsa di Dinas Kesehatan Kota Yogyakarta. J Kebijak Kesehat Indones JKKI [Internet]. 2018;7(1):34-41. Available from: https://jurnal.ugm.ac.id/jkki/article/view/5367/21 520

9. Sreedhar A, Apte M, Mallya R. Pharmaceutical Waste Management. Int J Pharm Sci Rev Res [Internet]. 2018;52(1):82-6. Available from: https://search.proquest.com/docview/755266901
?accountid=12763\%0Ahttp://primoa.library.uns w.edu.au/openurl/61UNSW_INST/UNSW_SER VICES_PAGE?url_ver=Z39.88-

2004\&rft_val_fmt $=$ info:ofi/fmt:kev:mtx:disserta tion\&genre $=\overline{\text { dissertations }}+\% 26+$ theses $\&$ sid $=$ Pro Q:ProQuest+Dis

10. Jovanović V, Manojlović J, Jovanović D, Matic B, Đonović N. Management of pharmaceutical waste in hospitals in Serbia - Challenges and the potential for improvement. Indian J Pharm Educ Res [Internet]. 2016;50(4):695-702. https://doi.org/10.5530/ijper.50.4.22

11. Rudiyanto A. Pengaruh COVID-19 terhadap Tujuan Pembangunan Berkelanjutan [Internet]. 2020 p. 1-64. Available from: https://kkp.go.id/an-component/media/uploadgambar-pendukung/DitJaskel/publikasi-materi2/SDGs-Talks-Menjaga-Momentum/20200506 Final Paparan Deputi KSDA SDG IPB - sec.pdf

12. Syahreni D, Ardiningtyas B. Gambaran Penyebab dan Kerugian karena Obat Rusak dan Kedaluarsa [Internet]. Yogyakarta; 2016. Available from: http://etd.repository.ugm.ac.id/penelitian/detail/1 08215

13. WHO. Panduan Pembuangan Limbah Perbekalan Farmasi [Internet]. Bahasa Ind. Widyastuti P, editor. Jakarta: Penerbit Buku Kedokteran EGC; 2003. 61 p. Available from: http://apps.who.int/iris/bitstream/handle/10665/4 2238/WHO_EDM_PAR_99.2_ind.pdf;jsessionid $=\mathrm{D} 77 \mathrm{~B} 268 \mathrm{~B} 5 \mathrm{~B} 00 \overline{\mathrm{E}} \mathrm{AEAA} 3 \mathrm{C}$ C415D1AA41985? sequence $=2$

14. Wahyudi W. Tanggungjawab Hukum Apoteker dalam Pemusnahan Obat Narkotika di Rumah Sakit. Soumatera Law Rev [Internet]. 2019;2(2):309.

https://doi.org/10.22216/soumlaw.v2i2.4484

15. Dewi TL. Gambaran Pengelolaan Obat Rusak Dan Kadaluarsa Di Apotek Pradipta Slawi [Internet]. Politeknik Harapan Bersama; 2021. Available from: https://view.officeapps.live.com/op/view.aspx?sr $\mathrm{c}=\mathrm{http} \% 3 \mathrm{~A} \% 2 \mathrm{~F} \% 2 \mathrm{Feprints}$.poltektegal.ac.id $\% 2$ F140\%2F1\%2FGambaran\%2520Pengelolaan\%2 520Obat\%2520Rusak\%2520Dan\%2520Kadalua rsa\%2520Di\%2520Apotek\%2520Pradipta\%252 0Slawi.docx\&wdOrigin=BROWSELINK

16. Kareri DR. Pelaporan Obat Rusak dan Kadaluarsa di Seksi Kefarmasian Dinas Kesehatan Kabupaten Sumba Timur [Internet]. Karya Tulis Ilmiah. Poltekkes Kemenkes Kupang; 2018. Available from: http://repository.poltekeskupang.ac.id/365/

17. Nuraini WF. Analisa Pengelolaan Obat Kadaluarsa Di Instalasi Farmasi Rumah Sakit Umum Daerah Sukoharjo Tahun 2011 [Internet]. Universitas Sebelas Maret; 2013. Available from: https://digilib.uns.ac.id/dokumen/detail/33461 
18. Dyahariesti N, Yuswantina R. Evaluasi Keefektifan Pengelolaan Obat di Rumah Sakit. Media Farm Indones [Internet]. 2019;14(1):1-8. Available from: http://stifar.ac.id/ojs/index.php/MFI/article/view/ $109 / 90$

19. Mardiana D. Penanganan obat di Puskesmas Gerung. Pharm Tradit Med [Internet]. 2017;1(1):6-17.

https://doi.org/10.33475/jikmh.v6i1.63

20. Kemenkes RI KR. Pedoman Pengelolaan Obat Rusak dan Kadaluarsa di Fasilitas Pelayanan Kesehatan dan Rumah Tangga [Internet]. Direktorat Jenderal Kefarmasian dan Alat Kesehatan D, editor. Jakarta: Kementerian Kesehatan RI; 2021. 1-75 p. Available from: https://farmalkes.kemkes.go.id/2021/09/pedoma n-pengelolaan-obat-rusak-dan-kedaluwarsa-difasyankes-dan-rumah-tangga/

21. Arisma N. Gambaran Pengelolaan Limbah Medis Padat Di Rumah Sakit Hi Muhammad Yusuf Kalibalangan Kotabumi Tahun 2019. Ruwa Jurai J Kesehat Lingkung. 2021;15(2):85. https://doi.org/10.26630/rj.v15i2.2808

22. Misgiono M, Setiani O, Budiono B. Evaluasi Manajemen Limbah Padat Dan Cair Di Rsud
Mimika. J Kesehat Lingkung Indones [Internet]. 2016;13(1):1-13. Available from: https://ejournal.undip.ac.id/index.php/jkli/article/ viewFile/10010/7973

23. Manojlović J, Jovanović V, Georgiev AM, Tesink JG, Arsić T, Marinković V. Pharmaceutical waste management in pharmacies at the primary level of health care in serbia situation analysis. Indian J Pharm Educ Res [Internet]. 2015;49(2):106-11. https://doi.org/10.5530/ijper.49.2.5

24. Imarhia F, Varisco TJ, Wanat MA, Thornton JD. Prescription drug disposal: Products available for home use. J Am Pharm Assoc [Internet]. 2020;60(4):e7-13. Available from: https://doi.org/10.1016/j.japh.2020.01.004

25. Varisco TJ, Fleming ML, Bapat SS, Wanat MA, Thornton D. Health care practitioner counseling encourages disposal of unused opioid medications. J Am Pharm Assoc [Internet]. 2019;59(6):809-815.e5. Available from: https://doi.org/10.1016/j.japh.2019.07.010

26. FIP. Sustainability. Int Pharm J [Internet]. 2011;27(1):52. Available from: https://www.fip.org/files/fip/IPJ/IPJ_Vol27_No1 _web_def.pdf 